\title{
Risk Factors for Adult Overweight and Obesity: The Importance of Looking Beyond the 'Big Two'
}

\author{
Jean-Philippe Chaput ${ }^{\mathrm{a}} \quad$ Anders M. Sjödin $^{\mathrm{a}} \quad$ Arne Astrup $^{\mathrm{a}} \quad$ Jean-Pierre Després $^{\mathrm{b}}$ \\ Claude Bouchard ${ }^{\mathrm{C}}$ Angelo Tremblay $^{\mathrm{d}}$ \\ ${ }^{a}$ Department of Human Nutrition, Faculty of Life Sciences, University of Copenhagen, Copenhagen, Denmark \\ ${ }^{\mathrm{b}}$ Institut universitaire de cardiologie et de pneumologie de Québec, Quebec City, QC, Canada \\ ${ }^{c}$ Human Genomics Laboratory, Pennington Biomedical Research Center, Baton Rouge, LA, USA \\ ${ }^{\mathrm{d}}$ Division of Kinesiology, Department of Social and Preventive Medicine, Faculty of Medicine, Laval University, Quebec City, QC, Canada
}

\begin{abstract}
Keywords
Calcium intake - Eating behavior - Fat intake .

Physical activity participation - Sleep duration .

Weight gain
\end{abstract}

\section{Summary}

Objective: To compare two traditional (high dietary lipid intake and non-participation in high-intensity physical exercise, namely the 'Big Two' factors) versus three nontraditional (short sleep duration, high disinhibition eating behavior, and low dietary calcium intake) risk factors as predictors of excess body weight and overweight/obesity development. Method: Adult participants aged 18-64 years of the Quebec Family Study were selected for cross-sectional ( $n=537$ ) and longitudinal ( $n=283$; 6-year follow-up period) analyses. The main outcome measure was overweight/obesity, defined as a $\mathrm{BMI} \geq 25 \mathrm{~kg} / \mathrm{m}^{2}$. Results: We observed that both the prevalence and incidence of overweight/obesity was best predicted by a combination of risk factors. However, short sleep duration, high disinhibition eating behavior and low dietary calcium intake seemed to contribute more to the risk of overweight and obesity than high dietary lipid intake and non-participation in high-intensity physical exercise. Globally, the risk of being overweight or obese was two-fold higher for individuals having the three nontraditional risk factors combined (OR 6.05; 95\% $\mathrm{Cl}$ 4.26-7.88) compared to those reporting a high percentage of lipids in their diet together with no vigorous physical activity in their daily schedule (OR 2.95; 95\% Cl 2.18-3.73). Furthermore, the risk of overweight/obesity was also higher for the combination of any two of the nontraditional risk factors than for the combination of the 'Big Two' factors. Conclusion: These results are concordant with previous reports showing that obesity is a multifactorial condition, and emphasize the importance of looking beyond reported measures of the 'Big Two' factors.

\section{Introduction}

It is a truism that the positive energy balance underlying obesity is attributable to excess energy intake and insufficient energy expenditure. Thus, physical inactivity and unhealthy diet are the 'Big Two' on which almost all preventive and therapeutic programs for obesity are focused. However, attempts to prevent or manage obesity based on these traditional risk factors have been generally unsuccessful, and the obesity crisis rages on. Systematic reviews and meta-analyses on dietary fat suggest that a weight loss of $\sim 3-5 \mathrm{~kg}$ can be expected with a reduction in the proportion of energy from dietary fat of 10 percentage points (e.g. from 40 to $30 \%$ ) [1-3]. Estimates of the effect of exercise training or physical activity level on body weight have been reported to be modest [4, 5]. As recently reviewed, it is clear that multiple plausible causes of obesity exist outside of the conventional 'Big Two' [6-8].

Recent results showed that short sleep duration was the most important risk factor for overweight and obesity in a cohort of children aged between 5 and 10 years [9]. Indeed, excess body weight was predicted by short sleep duration, with odds ratios exceeding those of other well-known risk factors, including parental obesity, television viewing, socioeconomic status and physical inactivity. Likewise, in another study,

\section{KARGER}

Fax +497614520714

Information@Karger.de

www.karger.com

\section{(C) 2010 S. Karger GmbH, Freiburg}

Accessible online at:

www.karger.com/ofa 
three nontraditional risk factors for adult overweight/obesity and weight gain were identified, namely short sleep duration, low dietary calcium intake, and high disinhibition eating behavior [10]. These new correlates of obesity are understudied mainly because they do not have a caloric value per se.

The present study aimed at comparing the predictive value of two traditional (high dietary lipid intake and non-participation in high-intensity physical exercise) and three nontraditional (short sleep duration, high disinhibition eating behavior and low dietary calcium intake) risk factors for obesity. Furthermore, we verified whether there were additive or synergetic effects among these factors. The study was undertaken with the cross-sectional design cohort of the Quebec Family Study as well as with its 6-year follow-up sample.

\section{Subjects and Methods}

\section{Subjects}

The Quebec Family Study was initiated at Laval University, Quebec City, in 1978 [11]. The primary objective of this study was to investigate the role of genetic factors in the etiology of obesity, fitness and cardiovascular and diabetes risk factors. In phase 1 of the study (1978-1981), a total of 1,650 individuals from 375 families were recruited and measured. Recruitment was conducted irrespective of body weight during phase 1 , which resulted in a cohort with a wide range of BMI (between 13.8 and $\left.64.9 \mathrm{~kg} / \mathrm{m}^{2}\right)$. In phases 2 (1989-1994) and 3 (1995-2001), 100 families from phase 1 were re-tested, and additional 123 families with at least one parent and one offspring with a BMI of $\geq 32 \mathrm{~kg} / \mathrm{m}^{2}$ were added to the cohort.
These Caucasian families were recruited through the media and were all French Canadians from the greater Quebec City area. The present analyses are based on participants in phases 2 and 3 . Individuals who were between 18 and 64 years of age were selected for cross-sectional analyses (230 men and 307 women). Furthermore, 121 men and 162 women on whom follow-up data were available were retained for prospective analyses (mean duration of follow-up: $6.0 \pm 0.9$ years). Additional inclusion criteria were: i) nonsmoker; ii) not pregnant; iii) stable body weight ( $\pm 2 \mathrm{~kg}$ ) over the 6 months preceding testing; and iv) no metabolic disease (e.g. diabetes, hypertension) or no medication that could interfere with the outcome variable. In addition, subjects with missing data were excluded. All subjects provided written informed consent to participate in the study. The project was approved by the Medical Ethics Committee of Laval University.

\section{Anthropometric Variables}

Height was measured to the nearest $0.1 \mathrm{~cm}$ using a standard stadiometer, and body weight was measured to the nearest $0.1 \mathrm{~kg}$ using a digital panel indicator scale (Beckman Industrial Ltd, Model 610/612, Scotland, UK). BMI was calculated as body weight divided by height squared $\left(\mathrm{kg} / \mathrm{m}^{2}\right)$. These anthropometric measurements were performed according to standardized procedures recommended at the Airlie Conference [12]. The main outcome measure was overweight/obesity, defined as a BMI $\geq 25 \mathrm{~kg} / \mathrm{m}^{2}$.

\section{Potential Risk Factors}

In this study, two traditional risk factors (i.e. high lipid intake and nonparticipation in high-intensity physical exercise) were compared to three nontraditional risk factors (i.e. short sleep duration, low dietary calcium intake and high dishinibition eating behavior). We chose to include high lipid intake and non-participation in high-intensity physical exercise in the models at the expense of other factors, e.g. total energy intake and moderate-intensity physical exercise, because they had the best predictive
Table 1. Prevalence of risk factors for the entire cohort sample and according to the body weight status ${ }^{\mathrm{a}}$

\begin{tabular}{|c|c|c|c|}
\hline & Overall $(\mathrm{n}=537)$ & $\begin{array}{l}\text { Normal weight }{ }^{\mathrm{b}} \\
(\mathrm{n}=268)\end{array}$ & $\begin{array}{l}\text { Overweight/obese } \\
(\mathrm{n}=269)\end{array}$ \\
\hline \multicolumn{4}{|l|}{ Traditional risk factors } \\
\hline Lipid intake $\geq 40 \%$ fat $/$ day & $107(19.9)$ & $46(17.2)$ & $61(22.7)^{* *}$ \\
\hline HIPE $0 \mathrm{~min} /$ day & $288(53.6)$ & $123(45.9)$ & $165(61.3)^{* *}$ \\
\hline $\begin{array}{l}\text { Two combined } \\
\geq 40 \% \text { fat } / \text { day }+0 \text { min of HIPE/day }\end{array}$ & $67(12.5)$ & $19(7.1)$ & $48(17.8)^{*}$ \\
\hline \multicolumn{4}{|l|}{ Nontraditional risk factors } \\
\hline Calcium intake $<600 \mathrm{mg} /$ day & $112(20.9)$ & $39(14.6)$ & $73(27.1)^{*}$ \\
\hline Eating behavior $\geq 6$ disinhibition score & $178(33.1)$ & $37(13.8)$ & $141(52.4)^{*}$ \\
\hline Sleep duration $<6 \mathrm{~h} /$ day & $82(15.3)$ & $19(7.1)$ & $63(23.4)^{*}$ \\
\hline $\begin{array}{l}\text { Calcium intake and eating behavior } \\
<600 \mathrm{mg} / \text { day }+\geq 6 \text { disinhibition score }\end{array}$ & $73(13.6)$ & $24(9.0)$ & $49(18.2)^{*}$ \\
\hline $\begin{array}{l}\text { Calcium intake and sleep duration } \\
<600 \mathrm{mg} / \text { day }+<6 \mathrm{~h} / \text { day }\end{array}$ & $42(7.8)$ & $4(1.5)$ & $38(14.1)^{*}$ \\
\hline $\begin{array}{l}\text { Eating behavior and sleep duration } \\
\geq 6 \text { disinhibition score }+<6 \mathrm{~h} / \text { day }\end{array}$ & $51(9.5)$ & $9(3.4)$ & $42(15.6)^{*}$ \\
\hline $\begin{array}{l}\text { Three combined } \\
\quad<600 \mathrm{mg} \text { of calcium/day }+ \\
\quad \geq 6 \text { disinhibition score }+<6 \text { h of sleep/day }\end{array}$ & $26(4.8)$ & $2(0,007)$ & $24(8.9)^{*}$ \\
\hline
\end{tabular}

HIPE = High-intensity physical exercise.

${ }^{a}$ Data are given as $\mathrm{n}(\%)$. Descriptive characteristics were compared by $\chi^{2}$ test.

${ }^{\mathrm{b}}$ BMI between 18.5 and $24.9 \mathrm{~kg} / \mathrm{m}^{2}$.

${ }^{\mathrm{c}} \mathrm{BMI} \geq 25 \mathrm{~kg} / \mathrm{m}^{2}$.

$* \mathrm{P}<0.01$ versus normal-weight individuals.

$* * \mathrm{P}<0.05$ versus normal-weight individuals. 
Fig. 1. Adjusted associations of a traditional and $\mathbf{b}$ nontraditional risk factors with adult overweight/obesity in the cross-sectional sample. Model adjusted for age, sex, and socioeconomic status. $\mathrm{OR}=$ odds ratio; $\mathrm{CI}=$ confidence interval. High Lipid Intake ( $\geq 40 \%$ fat/day vs. $<30 \%$ fat/day); No HIPE, non-participation in highintensity physical exercise ( $0 \mathrm{~min} /$ day vs. $\geq 30 \mathrm{~min} /$ day); High Lipid Intake + No HIPE ( $\geq 40 \%$ fat/day and $0 \mathrm{~min}$ of HIPE/day vs. $<30 \%$ fat/day and $\geq 30 \mathrm{~min}$ of HIPE/day); LCI, low calcium intake ( $<600 \mathrm{mg} /$ day vs. $\geq 1,000 \mathrm{mg} /$ day); HDEB, high disinhibition eating behavior ( $\geq 6$ disinhibition score vs. $\leq 3$ disinhibition score); SSD, short sleep duration ( $<6$ h/day vs. $7-8$ h/day $) ; \mathrm{LCI}+$ HDEB ( $<600 \mathrm{mg}$ of calcium/day and $\geq 6$ disinhibition score vs. $\geq 1,000 \mathrm{mg}$ of calcium/day and $\leq 3$ disinhibition score) LCI + SSD ( $<600 \mathrm{mg}$ of calcium/day and $<6$ h of sleep/day vs. $\geq 1,000 \mathrm{mg}$ of calcium/day and $7-8 \mathrm{~h}$ of sleep/day); HDEB + SSD ( $\geq 6$ disinhibition score and $<6$ h of sleep/day vs. $\leq 3$ disinhibition score and $7-8 \mathrm{~h}$ of sleep/day); LCD + HDEB + SSD (<600 mg of calcium/day combined with $\geq 6$ disinhibition score and $<6 \mathrm{~h}$ of sleep/day vs. $\geq 1,000 \mathrm{mg}$ of calcium/day combined with $\leq 3$ disinhibition score and $7-8 \mathrm{~h}$ of sleep/day). $\mathrm{n}=537$ (230 men and 307 women). $* \mathrm{P}<0.01 ; * \mathrm{P}<0.05$.
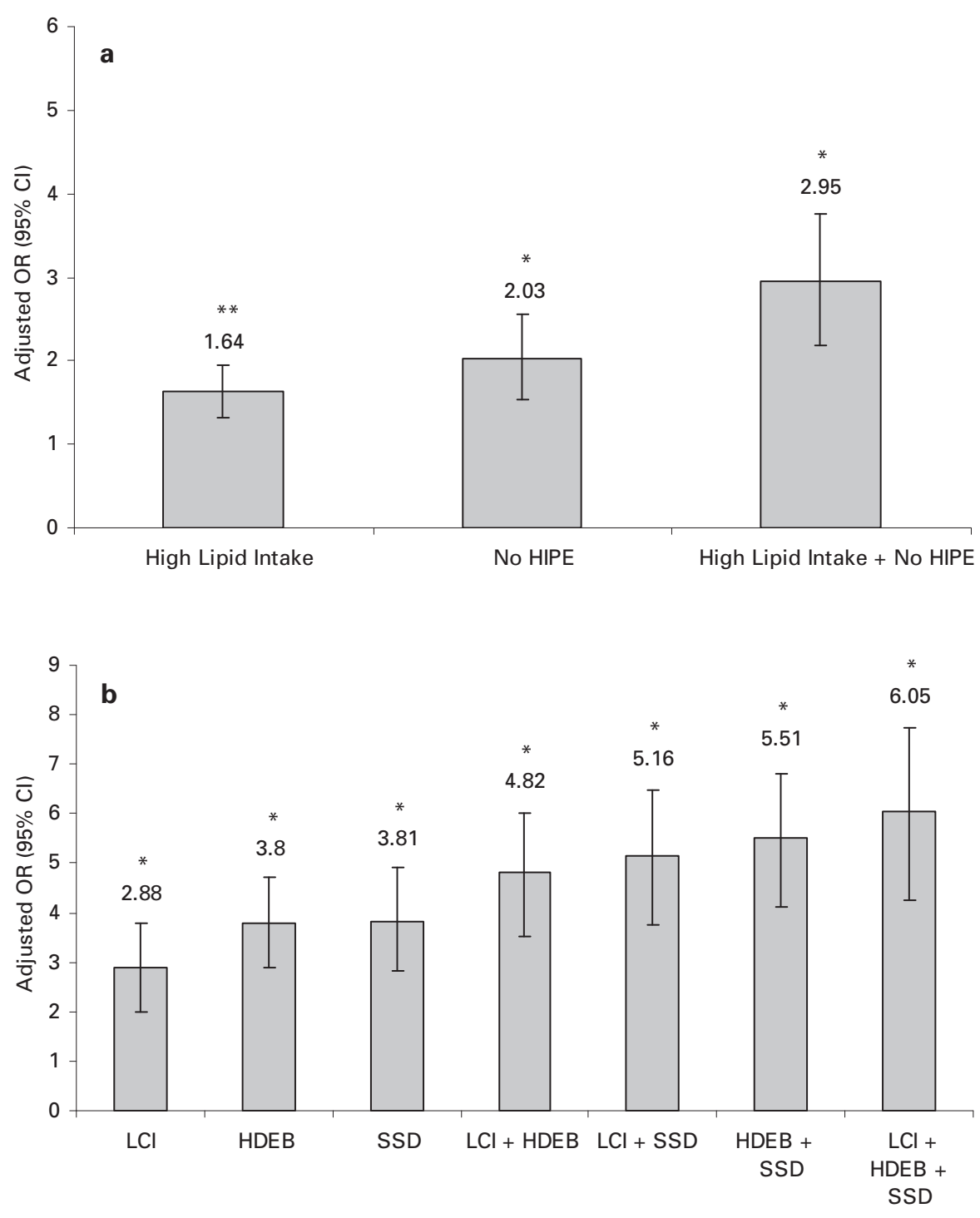

power for overweight/obesity in this cohort. Lipid and calcium intake were estimated with a 3-day food record, including 2 week days and 1 weekend day. Participants were shown how to complete this record by a dietician who provided instruction about measuring the quantities of ingested foods. This method of dietary assessment has been shown to provide reliable estimates of dietary habits in this population [13]. Mean daily intake was estimated by a dietician using the computerized version of the Canadian Nutrient File [14]. Disinhibition eating behavior (overconsumption of food in response to cognitive or emotional cues) was assessed using the Three-Factor Eating Questionnaire [15], as validated for the French population [16]. The Three-Factor Eating Questionnaire has been shown to have acceptable reliability and validity $[15,17]$. Daily physical activity level and pattern were evaluated with a 3-day physical activity diary, as previously described [18]. Briefly, subjects recorded the dominant activity for each 15 -min period over $24 \mathrm{~h}$ based on a listing of activities classified on a 1-9 scale, with 1 corresponding to activities of very low energy expenditure such as sleeping and 9 to activities of very high energy expenditure such as running. Participation in high-intensity physical exercise was estimated as the number of periods graded 8 and 9 over the 3 days and was used for statistical analyses. The reliability and the validity of the record have been previously reported [18]. Finally, the number of hours of sleep was assessed through a question inserted in a self-administered questionnaire. The question formulation was: 'On aver- age, how many hours do you sleep a day?' The socioeconomic status of participants was obtained via a self-administered questionnaire. Employment status (student, paid employment, looking for work, home duties, retired, disabled), highest educational level (high school, junior college (CEGEP for Quebec), university) and total annual family income (categorized into 5 groups ranging from $\angle \mathrm{CAD} 10,000$ to $\mathrm{CAD} 70,000$ or more) were obtained. The dichotomization for each risk factor was chosen based on previous studies [19-25]. Briefly, the cut-off points for the 'at-risk' and 'reference' groups are $\geq 40 \%$ and $<30 \%$ dietary fat/day (lipid intake), 0 and $\geq 30 \mathrm{~min} /$ day (high-intensity physical exercise), $<6$ and $7-8 \mathrm{~h} /$ day (sleep duration), $<600$ and $\geq 1,000 \mathrm{mg} /$ day (calcium intake), and $\geq 6$ and $\leq 3$ disinhibition score (disinhibition eating behavior), respectively. Tertiles were used for the disinhibition eating behavior trait given that there is no consensus on what is considered a low or high score. The 'middle' level has not been included in the manuscript in order to improve clarity. All these factors were assessed at both baseline (phase 2) and year 6 (phase 3 ) in the longitudinal sample.

\section{Statistical Analysis}

The prevalence (\%) of risk factors was compared between normal-weight and overweight/obese individuals using the $\chi^{2}$ test. Logistic regression analysis was performed to evaluate the strength of the relationship between risk factors and adulthood overweight/obesity in the cross-sectional 
Fig. 2. Mean weight gain above baseline weight over the 6-year follow-up period for individuals in the $\mathbf{a}$ traditional and $\mathbf{b}$ nontraditional at-risk groups relative to the reference category.

Model adjusted for age, sex, baseline BMI, length of follow-up, and socioeconomic status. $\mathrm{CI}=$ confidence interval. High Lipid Intake ( $\geq 40 \%$ fat/day vs. $<30 \%$ fat/day); No HIPE, non-participation in high-intensity physical exercise ( $0 \mathrm{~min} /$ day vs. $\geq 30 \mathrm{~min} /$ day); High Lipid Intake + No HIPE $(\geq 40 \%$ fat/day and $0 \mathrm{~min}$ of HIPE/day vs. $<30 \%$ fat/day and $\geq 30 \mathrm{~min}$ of HIPE/day); LCI, low calcium intake ( $<600 \mathrm{mg} /$ day vs. $\geq 1,000 \mathrm{mg} /$ day); HDEB, high disinhibition eating behavior ( $\geq 6$ disinhibition score vs. $\leq 3$ disinhibition score); SSD, short sleep duration $(<6 \mathrm{~h} /$ day vs. $7-8 \mathrm{~h} /$ day $)$; LCI + HDEB ( $<600 \mathrm{mg}$ of calcium/day and $\geq 6$ disinhibition score vs. $\geq 1,000 \mathrm{mg}$ of calcium/day and $\leq 3$ disinhibition score $)$ : $\mathrm{LCI}+\mathrm{SSD}(<600 \mathrm{mg}$ of calcium/day and $<6 \mathrm{~h}$ of sleep/day vs. $\geq 1,000 \mathrm{mg}$ of calcium/day and $7-8 \mathrm{~h}$ of sleep/day); HDEB $+\operatorname{SSD}$ ( $\geq 6$ disinhibition score and $<6 \mathrm{~h}$ of sleep/day vs. $\leq 3$ disinhibition score and $7-8 \mathrm{~h}$ of sleep/day); LCD + HDEB + SSD (<600 mg of calcium/day combined with $\geq 6$ disinhibition score and $<6 \mathrm{~h}$ of sleep/day vs. $\geq 1,000 \mathrm{mg}$ of calcium/day combined with $\leq 3$ disinhibition score and $7-8 \mathrm{~h}$ of sleep/day). $\mathrm{n}=283$ (121 men and 162 women).
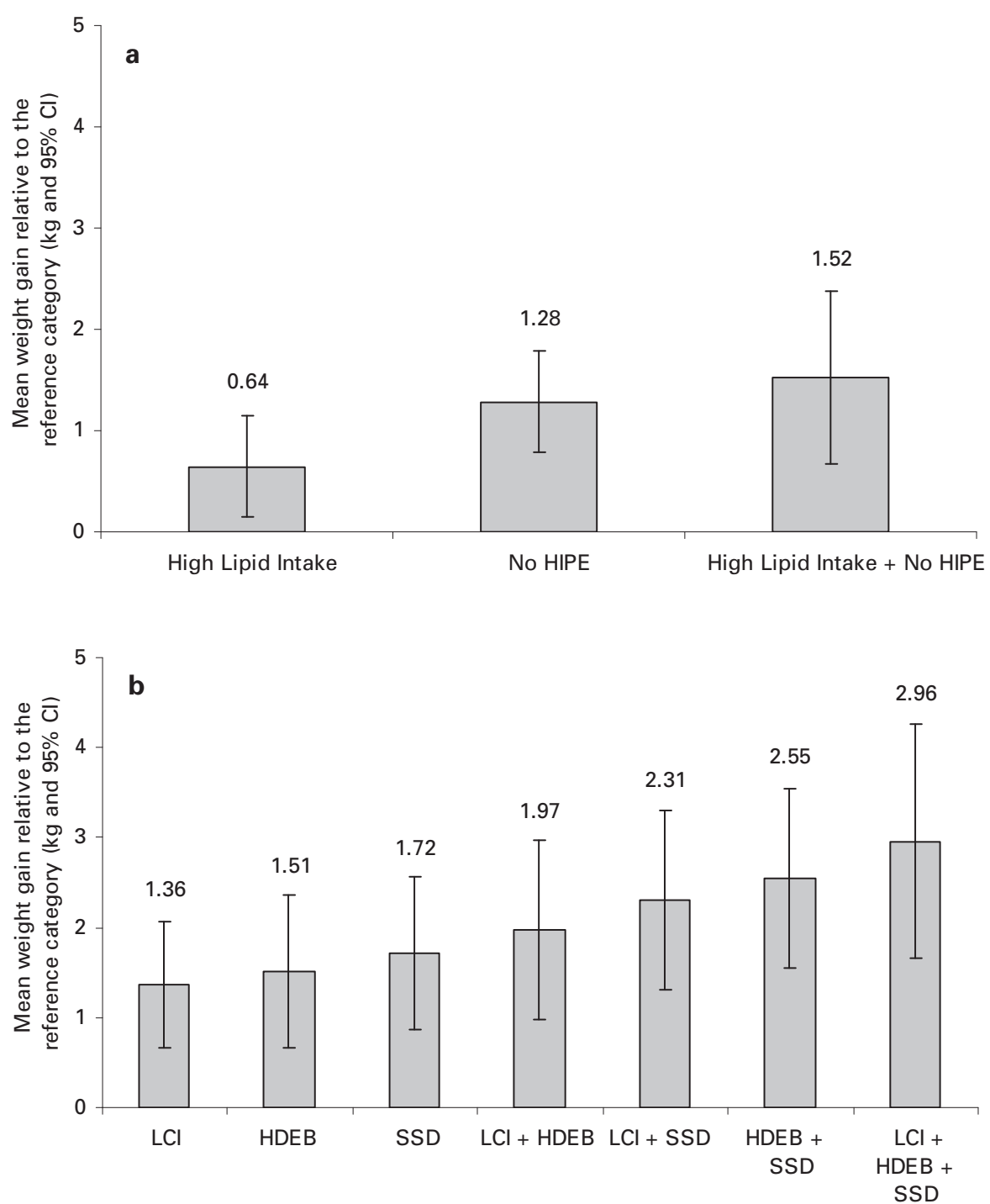

sample. In the longitudinal sample, logistic regression analysis was used to assess the association of risk factors with the development of overweight/obesity. Given that there was no sex interaction with the risk factors, all individuals were pooled together in order to improve clarity and statistical power. The models were adjusted for age, sex and socioeconomic status in the cross-sectional sample. In addition, multivariate linear regression modeling was used to estimate the mean weight gain above baseline weight over the 6-year follow-up period for individuals in the 'atrisk' groups relative to the gain in those included in the reference category. The model was adjusted for age, sex, baseline BMI, length of follow-up and socioeconomic status. Odds ratios (OR) and $95 \%$ confidence intervals $(95 \% \mathrm{CI})$ for both the prevalence and incidence of overweight/ obesity were calculated independently for each risk factor, with dummy variables for the reference category. Because some individuals in this family study are biologically related, we adjusted for clustering in the analyses to avoid underestimation of standard deviations using generalized estimating equations [26]. We modeled risk factors (exposure) and outcome (development of overweight/obesity) as repeated measures at 2 time points (baseline and 6 years later) in the longitudinal sample. A 2-tailed $\mathrm{P}$ value of less than 0.05 was considered to indicate statistical significance. All statistical analyses were performed using the JMP version 5.1.2 program (SAS Institute, Cary, NC, USA).

Risk Factors for Adult Overweight and Obesity

\section{Results}

\section{Cross-Sectional Results}

Among the 537 adult participants selected (57\% women, mean age 38.4 (SD 14.0), mean BMI 26.8 (SD 7.1)), 48\% had a paid employment and $25 \%$ had a university level. The prevalence of risk factors for the whole sample and according to the body weight status of participants is presented in table 1 . Overall, half of the cohort participants reported no high-intensity physical activity participation, and one third had a high disinhibition eating behavior trait. A significantly greater proportion of the overweight and obese participants exhibited the risk factors compared to those with a normal body weight. Multiple risk factors were more prevalent among the overweight/obese individuals. For example, a low calcium intake together with short sleep duration was more than 9 times more prevalent for the overweight/obese participants than for those with a normal body weight. Likewise, the combination of the three nontraditional risk factors was practically nonex- 
Table 2. Relationship between risk factors and incidence of adult overweight/obesity in the longitudinal sample

$\mathrm{OR}^{\mathrm{a}} \quad 95 \% \mathrm{CI}$

Traditional risk factors

Lipid intake $\geq 40 \%$ fat/day

HIPE 0 min/day

Two combined

$\geq 40 \%$ fat $/$ day +0 min of HIPE/day

\begin{tabular}{|c|c|c|}
\hline \multicolumn{3}{|l|}{ Nontraditional risk factors } \\
\hline Calcium intake $<600 \mathrm{mg} /$ day & $2.18 *$ & $1.17-3.26$ \\
\hline Eating behavior $\geq 6$ disinhibition score & $2.76^{*}$ & $1.48-4.10$ \\
\hline Sleep duration $<6 \mathrm{~h} /$ day & $2.97 *$ & $1.68-4.34$ \\
\hline $\begin{array}{l}\text { Calcium intake and eating behavior } \\
<600 \mathrm{mg} / \text { day }+\geq 6 \text { disinhibition score }\end{array}$ & $3.76^{*}$ & $2.31-5.39$ \\
\hline $\begin{array}{l}\text { Calcium intake and sleep duration } \\
<600 \mathrm{mg} / \text { day }+<6 \mathrm{~h} / \text { day }\end{array}$ & $4.02 *$ & $2.71-5.46$ \\
\hline $\begin{array}{l}\text { Eating behavior and sleep duration } \\
\quad \geq 6 \text { disinhibition score }+<6 \mathrm{~h} / \text { day }\end{array}$ & $4.49 *$ & $3.06-6.06$ \\
\hline $\begin{array}{l}\text { Three combined } \\
\quad<600 \mathrm{mg} \text { of calcium/day }+ \\
\quad \geq 6 \text { disinhibition score }+<6 \text { h of sleep/day }\end{array}$ & $4.92 *$ & $3.22-6.73$ \\
\hline
\end{tabular}

HIPE $=$ High-intensity physical exercise

${ }^{\mathrm{a}}$ Odds ratios (OR) calculated by logistic regression analysis. Model

adjusted for age, sex, baseline BMI, length of follow-up, and socio-

economic status. The calculations were performed for the 'at-risk'

compared to the 'reference' groups among the 151 subjects who were not overweight or obese at baseline.

$* \mathrm{P}<0.01$.

$* * \mathrm{P}<0.05$.

istent among the normal-weight individuals, whereas $8.9 \%$ of those having a BMI greater than $25 \mathrm{~kg} / \mathrm{m}^{2}$ had this trio of risk factors.

Figure 1 compares the traditional (Big Two) to the nontraditional risk factors for the prevalence of adult overweight/ obesity. We observed that the combination of the 'Big Two' factors together was a stronger predictor of overweight and obesity than each factor alone. Likewise, the combination of nontraditional risks factors gave a better prediction of overweight/obesity than each factor taken separately. In this cohort, high disinhibition eating behavior and short sleep duration were better predictors of overweight/obesity alone than high dietary lipid intake and non-participation in high-intensity physical exercise combined together. Globally, the risk of being overweight or obese was two-fold higher for those having the three nontraditional risk factors combined (OR 6.05; 95\% CI 4.26-7.88) compared to those having a high percentage of lipids in their diet together with no vigorous physical activity in the daily schedule (OR 2.95; 95\% CI 2.18-3.73).

\section{Longitudinal Results}

Figure 2 shows the mean weight gain above baseline weight over the 6-year follow-up period for individuals in the 'at-risk' groups relative to the gain in those included in the reference category. After adjustment for age, sex, baseline BMI, length of follow-up and socioeconomic status, those having the 'Big Two' factors (combination of high dietary lipid intake and non-participation in high-intensity physical exercise) gained $1.52 \mathrm{~kg}(95 \%$ CI $0.67-2.41 \mathrm{~kg})$ more than did those reporting eating less than $30 \%$ of dietary fat and doing more than 30 min of vigorous physical activity a day. Interestingly, those with the trio of nontraditional risk factors combined (low calcium intake, high disinhibition eating behavior and short sleep duration) gained about twice the weight over 6 years compared to those exhibiting the 'Big Two' factors (2.96 vs. $1.52 \mathrm{~kg})$.

A total of 132 subjects ( $46.6 \%$ of the prospective cohort) were overweight or obese at baseline, defined as a BMI of $\geq 25 \mathrm{~kg} / \mathrm{m}^{2}$. Among the 151 subjects who were not overweight or obese at baseline, 39 new cases of obesity (25.8\%) were identified over the 6-year follow-up period. As shown in table 2 , the risk of developing overweight or obesity was greater for individuals with the nontraditional than for those with the traditional risk factors. In particular, the risk of developing overweight or obesity was about the same for the two traditional risk factors combined (OR 2.66; 95\% CI 1.59-3.79) than for short sleep duration alone (OR 2.97; 95\% CI 1.68-4.34). Moreover, the incidence of overweight/obesity for individuals with the three nontraditional risk factors combined (OR 4.92; 95\% CI 3.22-6.73) was about twice as more frequent than for those characterized by a high percentage of dietary lipids coupled with no vigorous physical activity participation (OR 2.66; 95\% CI 1.59-3.79). We also observed that the incidence of overweight/obesity was best predicted when all risk factors were combined.

\section{Discussion}

This study compared two traditional and three nontraditional risk factors for obesity for their predictive values. We observed that both the prevalence and incidence of overweight/obesity were best predicted by a combination of risk factors. In this cohort of adults, short sleep duration, high disinhibition eating behavior and low dietary calcium intake appeared to have a greater contribution to overweight and obesity than high dietary lipid intake and non-participation in high-intensity physical exercise. This suggests that health practitioners and clinicians may need to consider a broader range of influential factors to more adequately address the obesity epidemic.

The obesity problem is multifaceted and requires a combination of measures in order to be managed. Epidemiologic research suggests that the 'Big Two' leaves a considerable amount of the total variance in adiposity phenotypes unexplained [6-8]. These observations combined with the results of this study suggest that the focus on the 'Big Two' factors as cornerstones of obesity prevention and treatment may repre- 
sent a rather narrow perspective. A careful examination of our results shows that non-participation in high-intensity physical activity was the most prevalent risk factor in this cohort $(53.6 \%)$, suggesting that targeting this factor at a population level may reach a more important number of individuals. On the other hand, despite the fact that the prevalence of short sleep duration is relatively low $(15.3 \%)$, short sleep remains present in a meaningful number of individuals. Recent results indicate that $5-13 \%$ of the total proportion of obesity in children and 3-5\% in adults could be attributable to short sleep [27]. However, we do not know yet if increasing sleep time in sleep-deprived obese individuals would reduce the amount of body fat or influence the level of hormones that help to control appetite. Furthermore, whether people can voluntarily change their sleeping hours is unknown.

The interest in the topic of sleep duration was fueled by the apparent paradox that a greater propensity to negative energy balance should theoretically be observed with fewer hours of sleep. However, one has observed a reduction in sleeping times over the past decades, as the prevalence of obesity was increasing [28]. Recent reviews and meta-analyses consistently reported that short sleep duration is associated with weight gain and obesity in children and adults [29-32]. Interventional studies have begun to identify mechanistic explanations for the deleterious effects of sleep deprivation on health. For instance, short-term partial sleep restriction leads to alterations in metabolic and endocrine functions including decreased glucose tolerance, insulin resistance, increased sympathetic tone, elevated cortisol concentrations, elevated levels of pro-inflammatory cytokines and decreased leptin and increased ghrelin levels [33-35]. Furthermore, abnormal sleepwake patterns alter intracellular circadian clocks that may potentiate disrupted metabolism [36]. Hence, chronic lack of sleep is stressful and biologically demanding. Studies examining the effects of restricted sleep on both sides of the energy balance equation (particularly in the young) with objective measures of sleep duration and quality are needed to establish the cause-and-effect relationship behind these findings.

Another important nontraditional risk factor, disinhibition, reflects a tendency towards overeating and eating opportunistically. Examples include eating in response to negative affect, overeating when others are eating, not being able to resist stimulation to eat and overeating in response to the palatability of food. However, the study of eating behavior has been dominated over the past 30 years by the concept of dietary restraint. Disinhibition as eating behavior trait has gradually received more attention because it is not only associated with increased weight and obesity, but also with mediating variables such as less healthful food choices, which contribute to overweight/obesity and poorer health [37-39]. Disinhibition is also predictive of poorer success at weight loss, and of weight regain after weight loss [40,41], and is associated with lower self-esteem [42], increased sedentary behavior [43] and poor psychological health [44]. Accordingly, our results as well as those of others [37] suggest that this behavioral trait is important to consider, with influences that go beyond eating behavior and relate to other behaviors potentially contributing to obesity.

Several studies have revealed an effect of dietary calcium on energy and fat balance and have emphasized the importance of an adequate intake of dairy foods, particularly skimmed and partly skimmed milk [45]. However, the mechanisms behind these associations are poorly defined. One popular hypothesis proposed that dietary calcium, via its influence on plasma 1,25-dihydroxyvitamin $\mathrm{D}_{3}$ (calcitriol) concentrations, regulates the concentrations of calcium within the adipocytes and, thereby, influences fat metabolism in the adipocytes [46]. According to this hypothesis, a low dietary calcium intake inhibits lipolysis, stimulates de novo lipogenesis and decreases fat oxidation. However, this view was refuted by other research groups $[47,48]$. Dietary calcium has also the capacity to bind lipids in the gastrointestinal tract and keep them unavailable for absorption, which in turn reduces postprandial lipemia and increases fecal fat excretion [49, 50]. Another important suggestion is that an effect of calcium supplement may be seen only in persons with a low habitual calcium intake [45]. Dairy food might also modulate body weight regulation by calcium-independent mechanisms. This is particularly the case for the well-known satiating effect of dairy proteins [51]. Newer research shows that humans possess taste receptors for calcium in the gastrointestinal tract and that signaling may be linked to appetite control [45]. Thus, the role of calcium in energy balance and obesity is not well understood. Future studies should address how calcium deficiency, which is often experienced during an energy-restricted weight-loss diet, can amplify hunger, impair compliance of participants and influence weight-loss outcome.

Strengths of this study include the use of both cross-sectional and longitudinal designs and the simultaneous testing of risk factors for overweight and obesity. Furthermore, data were available on both men and women, and we used an approach that should minimize confounding with repeated measures of both exposure and outcome. However, although cohort studies are well suited for the identification of associations, they cannot establish causality. Additionally, the Quebec Family Study was originally designed to explore the role of genetics in the etiology of obesity, fitness and cardiovascular and diabetes risk factors. Future work that is similar in design is needed on a larger sample that is more representative of Canadians from across the country for a better generalizability of the results obtained. We also have to keep in mind the limitations of questionnaire-based measurements that are inherent in epidemiological studies, as opposed to objective measures. The use of physical activity and diet recalls is tricky, and many researchers consider these reports to be inaccurate. Likewise, the validity of a single question for sleep duration is questionable and does not provide information on sleep quality. Finally, the risk factors for overweight and obesity are 
more numerous than those considered in this study, and the network of interactions between behavior, environment and genes in an ever-changing environment makes it difficult for epidemiologic studies to rule out reverse causation.

\section{Conclusions}

In summary, we observed that both the prevalence and incidence of overweight/obesity was best predicted by a combination of risk factors. Short sleep duration, high disinhibition eating behavior and low dietary calcium intake seemed to contribute more importantly to overweight and obesity than high dietary lipid intake and non-participation in high-intensity physical exercise. These findings suggest that we have much to understand before effective prevention and treatment strategies can be firmly grounded in science.

\section{Acknowledgements}

We express our gratitude to the subjects for their participation in the Quebec Family Study and the staff of the Physical Activity Sciences Laboratory at Laval University for their contribution to this study. We especially thank Dr. Germain Thériault, Guy Fournier, Monique Chagnon, Lucie Allard and Claude Leblanc for their help in the collection and analysis of the data. We acknowledge the financial support over 20 years of the Medical Research Council of Canada through several grants for the Quebec Family Study as well as other agencies from the governments of Quebec and Canada.

\section{Disclosure}

The authors declared no conflict of interest.

\section{References}

1 Yu-Poth S, Zhao G, Etherton T, Naglak M, Jonnalagadda S, Kris-Etherton PM: Effects of the National Cholesterol Education Program's Step I and Step II dietary intervention programs on cardiovascular disease risk factors: a meta-analysis. Am J Clin Nutr 1999;69:632-646.

2 Astrup A, Grunwald GK, Melanson EL, Saris WH, Hill JO: The role of low-fat diets in body weight control: a meta-analysis of ad libitum dietary intervention studies. Int J Obes Relat Metab Disord 2000;24:1545-1552.

3 Pirozzo S, Summerbell C, Cameron C, Glasziou P: Should we recommend low-fat diets for obesity? Obes Rev 2003;4:83-90.

4 Lemmens VE, Oenema A, Klepp KI, Henriksen $\mathrm{HB}$, Brug J: A systematic review of the evidence regarding efficacy of obesity prevention interventions among adults. Obes Rev 2008;9:446-455.

5 Shaw K, Gennat H, O'Rourke P, Del Mar C: Exercise for overweight or obesity. Cochrane Database Syst Rev 2006;18:CD003817.

6 McAllister EJ, Dhurandhar NV, Keith SW, Aronne LJ, Barger J, Baskin M, Benca RM, Biggio J, Boggiano MM, Eisenmann JC, Elobeid M, Fontaine KR, Gluckman P, Hanlon EC, Katzmarzyk P, Pietrobelli A, Redden DT, Ruden aDM, Wang C, Waterland RA, Wright SM, Allison DB: Ten putative contributors to the obesity epidemic. Crit Rev Food Sci Nutr 2009;49:868-913.

7 Tremblay A, Chaput JP: About unsuspected potential determinants of obesity. Appl Physiol Nutr Metab 2008;33:791-796.

8 Keith SW, Redden DT, Katzmarzyk PT, Boggiano MM, Hanlon EC, Benca RM, Ruden D, Pietrobelli A, Barger JL, Fontaine KR, Wang C, Aronne LJ, Wright SM, Baskin M, Dhurandhar NV, Lijoi MC, Grilo CM, DeLuca M, Westfall AO, Allison DB: Putative contributors to the secular increase in obesity: exploring the roads less traveled. Int $\mathrm{J}$ Obes (Lond) 2006;30:1585-1594.

$\checkmark$ Chaput JP, Brunet M, Tremblay A: Relationship between short sleeping hours and childhood overweight/obesity: results from the 'Québec en Forme' Project. Int J Obes (Lond) 2006;30:1080-1085.
10 Chaput JP, Leblanc C, Pérusse L, Després JP, Bouchard C, Tremblay A: Risk factors for adult overweight and obesity in the Quebec Family Study: have we been barking up the wrong tree? Obesity (Silver Spring) 2009;17:1964-1970.

11 Bouchard C: Genetic and body fat content. Prog Obes Res 1996;5:33-41.

12 The Airlie (VA) Consensus Conference: Standardization of Anthropometric Measurements. Champaign, Human Kinetics, 1988.

13 Tremblay A, Sévigny J, Leblanc C, Bouchard C: The reproducibility of a three-day dietary record. Nutr Res 1983;3:819-830.

14 Government of Canada: The Canadian Nutrient File. Ottawa, Canada, Health and Welfare Canada, 1990.

15 Stunkard AJ, Messick S: The three-factor eating questionnaire to measure dietary restraint, disinhibition and hunger. J Psychosom Res 1985;29:71-83.

16 Lluch A: Identification des conduites alimentaires par approaches nutritionnelles et psychométriques: implications thérapeutiques et préventives dans l'obésité humaine. $\mathrm{PhD}$ thesis, University of Nancy, France, 1995.

17 Laessle RG, Tuschl RJ, Kotthaus BC, Pirke KM: A comparison of the validity of three scales for the assessment of dietary restraint. J Abnorm Psychol 1989;98:504-507.

18 Bouchard C, Tremblay A, Leblanc C, Lortie G, Savard R, Thériault G: A method to assess energy expenditure in children and adults. Am J Clin Nutr 1983;37:461-467.

19 Tremblay A, Plourde G, Després JP, Bouchard C: Impact of dietary fat content and fat oxidation on energy intake in humans. Am J Clin Nutr 1989;49: 799-805.

20 Jacqmain M, Doucet E, Després JP, Bouchard C, Tremblay A: Calcium intake, body composition, and lipoprotein-lipid concentrations in adults. Am J Clin Nutr 2003;77:1448-1452.

21 Drapeau V, Provencher V, Lemieux S, Després JP, Bouchard C, Tremblay A: Do 6-y changes in eating behaviors predict changes in body weight? Results from the Québec Family Study. Int J Obes 2003;27: 808-814.
2 Provencher V, Drapeau V, Tremblay A, Després JP, Lemieux S: Eating behaviors and indexes of body composition in men and women from the Québec Family Study. Obes Res 2003;11:783-792.

23 Yoshioka M, Doucet E, St-Pierre S, Alméras N, Richard D, Labrie A, Després JP, Bouchard C, Tremblay A: Impact of high-intensity exercise on energy expenditure, lipid oxidation and body fatness. Int J Obes 2001;25:332-339.

24 Chaput JP, Després JP, Bouchard C, Tremblay A: Short sleep duration is associated with reduced leptin levels and increased adiposity: results from the Québec Family Study. Obesity 2007;15:253-261.

25 Chaput JP, Després JP, Bouchard C, Tremblay A: The association between sleep duration and weight gain in adults: a 6-year prospective study from the Quebec Family Study. Sleep 2008;31:517-523.

26 Hardin JW, Hilbe JM: Generalized Estimating Equations. New York, Chapman and Hall/CRC, 2003.

27 Young T: Increasing sleep duration for a healthier (and less obese?) population tomorrow. Sleep 2008;31:593-594.

28 Knutson KL, Van Cauter E: Associations between sleep loss and increased risk of obesity and diabetes. Ann N Y Acad Sci 2008;1129:287-304.

29 Nielsen LS, Danielsen KV, Sørensen TI: Short sleep duration as a possible cause of obesity: critical analysis of the epidemiological evidence. Obes Rev 2010; DOI: 10.1111/j.1467-789X.2010.00724.x.

30 Chen X, Beydoun MA, Wang Y: Is sleep duration associated with childhood obesity? A systematic review and meta-analysis. Obesity 2008;16:265-274.

31 Patel SR, Hu FB: Short sleep duration and weight gain: a systematic review. Obesity 2008;16:643-653.

32 Cappuccio FP, Taggart FM, Kandala NB, Currie A, Peile E, Stranges S, Miller MA: Meta-analysis of short sleep duration and obesity in children and adults. Sleep 2008;31:619-626.

33 Spiegel K, Leproult R, Van Cauter E: Impact of sleep debt on metabolic and endocrine function. Lancet 1999;354:1435-1439. 
34 Spiegel K, Tasali E, Penev P, Van Cauter E: Brief communication: sleep curtailment in healthy young men is associated with decreased leptin levels, elevated ghrelin levels, and increased hunger and appetite. Ann Intern Med 2004;141:846-850.

35 Knutson KL, Spiegel K, Penev P, Van Cauter E: The metabolic consequences of sleep deprivation Sleep Med Rev 2007;11:163-178.

-36 Bray MS, Young ME: Circadian rhythms in the development of obesity: potential role for the circadian clock within the adipocyte. Obes Rev 2007;8: 169-181.

-37 Bryant EJ, King NA, Blundell JE: Disinhibition: its effects on appetite and weight regulation. Obes Rev 2007;9:409-419.

38 Lahteenmaki L, Tuorila H: Three-factor eating questionnaire and the use and liking of sweet and fat among dieters. Physiol Behav 1995;57:81-88.

-39 Hays NP, Bathalon GP, McCrory MA, Roubenof R, Lipman R, Roberts SB: Eating behavior correlates of adult weight gain and obesity in healthy women aged 55-65 y. Am J Clin Nutr 2002;75:476483.

40 Karlsson J, Hallgren P, Kral J, Lindroos AK, Sjöström L, Sullivan M: Predictors and effects of long-term dieting on mental well-being and weight loss in obese women. Appetite 1994;23:15-26.
41 McGuire MT, Wing RR, Klem ML, Lang W, Hill JO: What predicts weight regain in a group of successful weight losers? J Consult Clin Psychol 1999; 67:185.

42 Brown K, Bryant E, Naslund E, King N, Blundell J: Traits that promote weight gain in obesity, bulimia nervosa and EDNOS. Obes Rev 2006;7:330.

43 Bryant EJ: Understanding disinhibition and its influences on eating behaviour and appetite. $\mathrm{PhD}$ thesis, University of Leeds, UK, 2006.

44 Provencher V, Bégin C, Piché ME, Bergeron J, Corneau L, Weisnagel SJ, Nadeau A, Lemieux S : Disinhibition, as assessed by the Three-Factor Eating Questionnaire, is inversely related to psychological well-being in postmenopausal women. Int J Obes 2007;31:315-320.

45 Major GC, Chaput JP, Ledoux M, St-Pierre S, Anderson GH, Zemel MB, Tremblay A: Recent developments in calcium-related obesity research. Obes Rev 2008;9:428-445.

46 Zemel MB, Shi H, Greer B, Dirienzo D, Zemel PC: Regulation of adiposity by dietary calcium. FASEB J 2000;14:1132-1138.
47 Bortolotti M, Rudelle S, Schneiter P, Vidal H Loizon E, Tappy L, Acheson KJ: Dairy calcium supplementation in overweight or obese persons: its effect on markers of fat metabolism. Am J Clin Nutr 2008;88:877-885.

48 Boon N, Hul GB, Stegen JH, Sluijsmans WE, Valle C, Langin D, Viguerie N, Saris WH: An intervention study of the effects of calcium intake on faecal fat excretion, energy metabolism and adipose tissue mRNA expression of lipid-metabolism related proteins. Int J Obes (Lond) 2007;31:1704-1712.

49 Lorenzen JK, Nielsen S, Holst JJ, Tetens I, Rehfeld J, Astrup A: Effect of dairy calcium or supplementary calcium on postprandial fat metabolism, appetite, and subsequent energy intake. Am J Clin Nutr 2007;85:678-687.

50 Christensen R, Lorenzen JK, Svith CR, Bartels EM, Melanson EL, Saris WH, Tremblay A, Astrup A: Effect of calcium from dairy and dietary supplements on faecal fat excretion: a meta-analysis of randomized controlled trials. Obes Rev 2009;10:475-486.

51 Astrup A, Chaput JP, Gilbert JA, Lorenzen JK: Dairy beverages and energy balance. Physiol Behav 2010;100:67-75. 